2014

\title{
Assessing the Flexibility of Research-Based Instructional Strategies: Implementing Tutorials in Introductory Physics in the Lecture Environment
}

Mila Kryjevskaia

Andrew Boudreaux

Western Washington University, andrew.boudreaux@wwu.edu

Dustin Heins

Follow this and additional works at: https://cedar.wwu.edu/physicsastronomy_facpubs

Part of the Physics Commons

\section{Recommended Citation}

Kryjevskaia, Mila; Boudreaux, Andrew; and Heins, Dustin, "Assessing the Flexibility of Research-Based Instructional Strategies: Implementing Tutorials in Introductory Physics in the Lecture Environment" (2014). Physics \& Astronomy. 6.

https://cedar.wwu.edu/physicsastronomy_facpubs/6 


\section{AMERICAN \\ JOURNAL \\ of PHYSICS}

\section{Assessing the flexibility of research-based instructional strategies: Implementing tutorials in introductory physics in the lecture environment}

Mila Kryjevskaia, Andrew Boudreaux, and Dustin Heins

Citation: American Journal of Physics 82, 238 (2014); doi: 10.1119/1.4863160

View online: http://dx.doi.org/10.1119/1.4863160

View Table of Contents: http://scitation.aip.org/content/aapt/journal/ajp/82/3?ver=pdfcov

Published by the American Association of Physics Teachers

\section{Articles you may be interested in}

The effect of research-based instruction in introductory physics on a common cognitive bias

AIP Conf. Proc. 1513, 138 (2013); 10.1063/1.4789671

A research-based curriculum for teaching the photoelectric effect

Am. J. Phys. 77, 87 (2009); 10.1119/1.2978181

Helping Preservice Teachers Implement and Assess Researchbased Instruction in K12 Classrooms AIP Conf. Proc. 790, 97 (2005); 10.1063/1.2084710

Study of TA's ability to implement the Tutorials in Introductory Physics and student conceptual understanding AIP Conf. Proc. 720, 161 (2004); 10.1063/1.1807279

Development and assessment of a research-based tutorial on light and shadow Am. J. Phys. 66, 906 (1998); 10.1119/1.18988

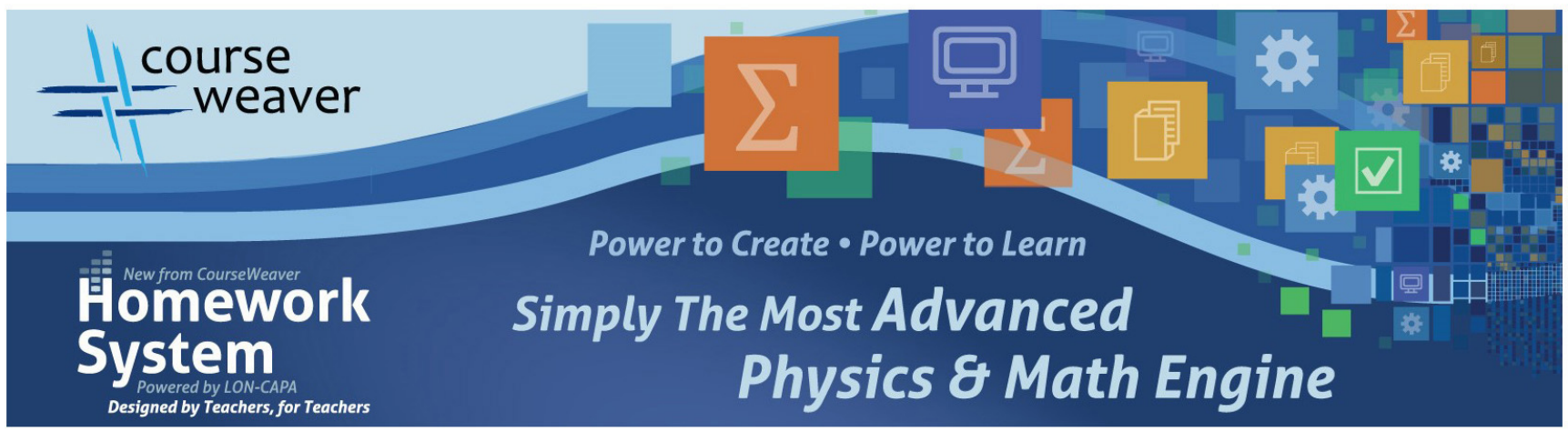




\title{
PHYSICS EDUCATION RESEARCH SECTION
}

The Physics Education Research Section (PERS) publishes articles describing important results from the field of physics education research. Manuscripts should be submitted using the web-based system that can be accessed via the American Journal of Physics home page, http://ajp.dickinson.edu, and will be forwarded to the PERS editor for consideration.

\section{Assessing the flexibility of research-based instructional strategies: Implementing tutorials in introductory physics in the lecture environment}

\author{
Mila Kryjevskaia \\ Department of Physics, North Dakota State University, Fargo, North Dakota 58108 \\ Andrew Boudreaux and Dustin Heins \\ Department of Physics and Astronomy, Western Washington University, Bellingham, Washington 98225
}

(Received 26 September 2012; accepted 23 December 2013)

\begin{abstract}
Materials from Tutorials in Introductory Physics, originally designed and implemented by the Physics Education Group at the University of Washington, were used in modified form as interactive lectures under conditions significantly different from those suggested by the curriculum developers. Student learning was assessed using tasks drawn from the physics education research literature. Use of tutorials in the interactive lecture format yielded gains in student understanding comparable to those obtained through the canonical tutorial implementation at the University of Washington, suggesting that student engagement with the intellectual steps laid out in the tutorials, rather than the specific strategies used in facilitating such engagement, plays the central role in promoting student learning. We describe the implementation details and assessment of student learning for two different tutorials: one focused on mechanical waves, used at North Dakota State University, and one on Galilean relativity, used at Western Washington University. Also discussed are factors that may limit the generalizability of the results. () 2014 American Association of Physics Teachers. [http://dx.doi.org/10.1119/1.4863160]
\end{abstract}

\section{INTRODUCTION}

Over the past 30 years, physics education researchers have developed curricula based on systematic investigation of student reasoning and conceptual understanding. These curricula focus on student thinking rather than the instructor's presentation of the ideas, build on known resources in students' reasoning, and target specific learning difficulties. Research and curriculum development have often occurred in a coordinated fashion with a single student population (e.g., introductory calculus-based physics students at a particular institution) and in a specific instructional setting (e.g., small group recitations taught by graduate teaching assistants). In many cases, materials have been assessed through administration of pre- and post-tests, and found to produce learning gains superior to those of traditional instruction.

Recent studies by Henderson and collaborators indicate that a growing number of physics faculty recognize the potential benefits of replacing some traditional instruction with learner-centered methods. ${ }^{1}$ However, some faculty aware of the effectiveness of these methods fail to implement them in their own courses. ${ }^{2}$ Identified barriers to implementation include both practical and intellectual constraints, including lack of resources (e.g., teaching assistant support, equipment, or classroom space), expectations of content coverage, resistance of students and/or teaching assistants (TAs) to non-traditional teaching styles, and departmental norms. ${ }^{3,4}$
This paper seeks to lower perceived barriers by documenting the learning gains that can be achieved when a physics education research-based curriculum is implemented in a new setting. This is part of an ongoing project with an overarching goal of investigating whether learning gains are primarily controlled by the substance and sequence of the intellectual content and the general engagement of students in going through the necessary thinking for themselves, or whether efficacy is sensitive to the implementation details. Such details could include, for example, the size of student groups and/or the number of teaching assistants facilitating students' small group work. If the learning gains associated with particular innovations are achievable in a variety of specific settings, then it may be reasonable to view researchbased approaches to instruction as frameworks or loose structures, rather than prescriptions. This view may in turn lead some faculty to regard implementation as more manageable. In this paper, we demonstrate that indeed it is possible to implement PER-based materials in a manner that fits specific institutional constraints and achieves student performance comparable to that reported by the developers.

We have implemented a comprehensive sequence of University of Washington (UW) tutorials at two institutions, North Dakota State University (NDSU) and Western Washington University (WWU). In each case, the format of tutorial instruction differed substantially from that suggested by the curriculum developers. This manuscript illustrates our findings by presenting assessment data on two specific 
topics: linear superposition and reflection of pulses on springs, and Galilean relativity.

Tutorials in Introductory Physics (TiIP), developed by the Physics Education Group at the University of Washington (UW PEG), is a set of research-based instructional materials designed to supplement a standard introductory physics course. ${ }^{5}$ Despite a growing body of evidence for the effectiveness of tutorials ${ }^{6-8}$ many institutions do not have sufficient resources to implement the tutorials in the manner in which they are used at UW. For example, the work reported in this paper was motivated by a lack of TA support in our local settings, a factor that is likely common to other institutions of similar rank. We have used the tutorials as interactive lectures in large enrollment calculus-based physics courses, a mode that differs from the UW approach in a variety of ways, including the ratio of instructors to students and the ratio of time spent in small group work to time spent in large group discussion. Our research goals included probing the extent to which the tutorials are effective when used in this manner.

Working criteria for success in the canonical implementation of tutorials have been established through extensive cycles of coordinated research, curriculum development, and classroom testing at UW. ${ }^{9}$ Typically, the percentage of correct responses on post-tests have converged to levels that, while not $100 \%$, have been regarded as satisfactory. We use these levels of student performance as criteria for judging the effectiveness of lecture-based implementation of tutorials at NDSU and WWU. As such, we compare post-test performance of students at NDSU and WWU with the reported post-test results from students who completed canonical tutorials at UW. We emphasize that NDSU and WWU students do not enter lecture-based tutorial instruction with greater levels of prior knowledge and understanding or with stronger general preparation. Two measures support this claim: comparable pretest performance of students at all three institutions, and comparable aggregated SAT and ACT admission scores [see Table III (Ref. 10)]. These baselines allow comparison of post-test performance at UW and our own institutions to serve as a means for evaluating the success of lecture-based tutorial implementation.

We hope that the results of this study will be informative for physics faculty who wish to introduce elements of interactive engagement in lecture-based courses. Instructors of courses that already involve the use of tutorials in the canonical, UW style may also benefit. The tutorial curriculum includes materials for a large set of topics, and instructors can choose tutorials that best support other course components. The identification of tutorials that are effective both in lecture-based and recitation formats will allow instructors to make informed decisions on the deployment of specific tutorials within a single course.

In Sec. II of the paper, we describe previous research on secondary implementations of Tutorials in Introductory Physics. Section III describes the specific implementations relevant to this study, while Sec. IV presents measurements of student understanding as evidence of the effectiveness of this instruction.

\section{PRIOR RESEARCH}

A large-scale secondary implementation of Tutorials in Introductory Physics has been undertaken at the University of Colorado at Boulder. This effort involved an instructional environment similar to that of the University of Washington and was structured to resemble the canonical implementation as closely as possible. Research has shown that the learning gains achieved at UW were, in general, reproduced at Colorado. ${ }^{6}$

The effectiveness of non-canonical TiIP implementations has also been studied. Recent work by Koenig et al. was motivated by limitations in resources for TA preparation and by TA skepticism about alternative instruction. ${ }^{7}$ The researchers questioned whether student-TA interactions are critical for the tutorials to be effective. The study was conducted in the context of the tutorial Changes in Energy and Momentum. ${ }^{11}$ Four different modes of recitation instruction were designed: (1) a traditional lecture taught by a physics faculty, (2) students working individually through the tutorial, (3) students working in groups of three or four through the tutorial, and (4) students working in groups of three or four through the tutorial with rigorously prepared TAs guiding students through the material by asking questions rather than by giving the answers. In styles 2 and 3, students received answer sheets upon completion of each activity. Style 4 was consistent with the canonical tutorial implementation discussed in detail below. The researchers found that the highest gains in student understanding were achieved only when the tutorial was implemented in the format suggested by the tutorial developers, Style 4.

At UW, in addition to the canonical implementation, tutorial materials are occasionally modified for use during interactive tutorial lectures in introductory algebra-based and upper-division physics courses. The reported percentage of correct answers obtained from students who participate in the interactive tutorial lecture is typically higher than for those who have traditional lecture instruction. ${ }^{12} \mathrm{~A}$ noncanonical implementation of Physics by Inquiry, ${ }^{13}$ a curriculum related to TiIP, was undertaken at the Evergreen State College and shown to produce learning gains comparable to primary implementations. ${ }^{14}$

\section{IMPLEMENTING TUTORIALS IN THE LECTURE SETTING}

This section contrasts the canonical implementation of TiIP with modified, lecture-based implementations at two different institutions. We start with a detailed description of how the tutorials are used at UW, a set of instructional practices not evident from the published materials alone. Then we describe the instructional setting of introductory physics lectures at NDSU and WWU. The instructors at each institution completed graduate work with the UW PEG and are thus well-acquainted with TiIP. Due primarily to a lack of TAsupported small group recitations, each instructor decided to implement the tutorials in lecture. Differences in the format of the lecture sections and in instructor approaches to engaging students with the material led to distinct implementations.

\section{A. Canonical implementation of TiIP}

At the University of Washington, the weekly 50-min recitation section of the introductory calculus-based physics course is devoted to Tutorials in Introductory Physics. Students work in groups of three or four through sequences of tasks and questions designed on the basis of research on student difficulties with the relevant physics content. The overarching goal of the tutorials is to promote functional understanding of concepts that are challenging for many students even after traditional instruction. ${ }^{15,16}$ Each sequence has specific learning targets, and a number of instructional strategies are used. Some 
Table I. Comparison of instructional approaches for canonical and lecture-based TiIP implementations.

Tutorial-based lectures

\begin{tabular}{|c|c|c|c|}
\hline \multirow[b]{2}{*}{ Instructional approaches } & \multirow[b]{2}{*}{ Canonical tutorials } & \multicolumn{2}{|c|}{ Tutorial-based lectures } \\
\hline & & NDSU & WWU \\
\hline Learning through guided inquiry & \multicolumn{3}{|c|}{ Students guided through same development of ideas } \\
\hline Intellectual engagement & $\begin{array}{l}\text { Small-group discussions are } \\
\text { primary }\end{array}$ & $\begin{array}{l}\text { Whole-class discussions are primary; } \\
\text { 4-6 clicker questions per lec. }\end{array}$ & $\begin{array}{l}\text { Balance of small group and whole } \\
\text { class discussion }\end{array}$ \\
\hline \multirow[t]{2}{*}{ Individually tailored feedback } & \multicolumn{3}{|c|}{ Instructor-student interactions guided by student responses to tutorial worksheet questions. } \\
\hline & $\begin{array}{l}\text { Two TAs interact with six groups of } \\
\text { 3-4 students each. }\end{array}$ & $\begin{array}{l}\text { Lecturer interacts with } \sim 180 \\
\text { students }\end{array}$ & $\begin{array}{l}\text { Lecturer interacts with } \sim 60 \text { stu- } \\
\text { dents }\end{array}$ \\
\hline \multirow[t]{4}{*}{ Opportunities for metacognition } & $\begin{array}{l}\text { Students modify reasoning based on } \\
\text { inconsistencies in own answers. }\end{array}$ & \multicolumn{2}{|c|}{$\begin{array}{l}\text { During whole-class discussion, few students receive tailored feedback. For } \\
\text { clicker questions, students receive feedback on their answer. }\end{array}$} \\
\hline & \multicolumn{3}{|c|}{$\begin{array}{l}\text { Hypothetical student dialogs allow examination of multiple reasoning approaches before evidence that supports a } \\
\text { specific approach is presented. }\end{array}$} \\
\hline & \multicolumn{3}{|c|}{ Pretest administered before instruction on each tutorial topic. } \\
\hline & $\begin{array}{l}\text { Students encouraged to revisit pret- } \\
\text { est upon completing tutorial. }\end{array}$ & $\begin{array}{r}\text { Pretest posed again during clas } \\
\text { discussed to } \mathrm{m}\end{array}$ & $\begin{array}{l}\text { and post-tutorial performance } \\
\text { arning explicit. }\end{array}$ \\
\hline
\end{tabular}

activities employ a strategy referred to as "elicit-confrontresolve-reflect." An initial question asks students to make a prediction about a particular situation; this serves to elicit student ideas. Students are then guided through the reasoning necessary to analyze the situation. Students are prompted to check their answers for consistency with observations or prior conclusions, and to reflect on their thinking paths. Other activities require students to synthesize and generalize ideas, or apply concepts in new situations.

Below we discuss general approaches to instruction that characterize canonical implementation of the tutorials. Table I lists these approaches and describes how they were incorporated in our large-lecture adaptation. Table II summarizes specific logistical features of tutorial implementation at UW, NDSU, and WWU. These features are discussed in detail in Sec. III B 2.

(1) Learning through guided inquiry. Tutorials facilitate logical development of ideas by providing step-by-step guidance through the reasoning needed to develop functional understanding.

(2) Intellectual engagement. Tutorials focus on student thinking rather than instructor presentation of ideas. Students develop their own understanding through discussions with peers and tutorial instructors.
(3) Individually tailored feedback. Tutorial sessions are led by a team of two rigorously prepared instructors, typically graduate TAs or advanced undergraduates. The instructors strive to provide formative feedback in real time by listening to student conversations, and then guiding students to deeper understanding through semiSocratic dialogue. Most question sequences culminate with a "check point" that prompts students to explain their thinking to an instructor. As warranted, TAs may pose challenge questions to push strong groups farther, or may revisit underlying ideas to solidify the learning of weaker groups. While TA preparation meetings typically suggest a repertoire of probing questions, a "script" is avoided in order to foster interactions that are authentically responsive to student thinking.

(4) Opportunities for metacognition. Tutorials provide frequent, "built-in" opportunities for students to analyze their own thinking. In particular, students are encouraged to reflect on the thinking paths they have used in constructing understanding. Specific tasks ask students to:

- Revise initial ideas. As part of the elicit-confrontresolve-reflect strategy, students evaluate their own thinking by identifying and resolving inconsistencies between emerging ideas and established results. Students may follow a problematic line of reasoning

Table II. Comparison of specific logistical features of tutorial implementation.

\begin{tabular}{|c|c|c|c|}
\hline \multirow[b]{2}{*}{ Details of implementation } & \multirow[b]{2}{*}{ Canonical tutorials } & \multicolumn{2}{|c|}{ Tutorial-based lectures } \\
\hline & & NDSU & WWU \\
\hline Pretests & \multicolumn{3}{|c|}{ Credit is awarded based on completeness (not correctness) } \\
\hline $\begin{array}{l}\text { Expectation of prior knowledge before } \\
\text { tutorial-based instruction }\end{array}$ & $\begin{array}{l}\text { Typically done after traditional lec- } \\
\text { ture and/or lab instruction on a topic }\end{array}$ & $\begin{array}{l}\text { Typically done before any instruction } \\
\text { on a topic }\end{array}$ & $\begin{array}{l}\text { Typically done after assigned reading } \\
\text { and lecture overview of key ideas } \\
\text { from the textbook chapter on a topic }\end{array}$ \\
\hline Tutorial worksheets (ungraded) & Required & $\begin{array}{l}\text { Not required, all questions displayed } \\
\text { on the screen one-by-one }\end{array}$ & Required \\
\hline Homework (graded) & $\begin{array}{l}\text { Paper-and-pencil HW follows each } \\
\text { tutorial session (students are required } \\
\text { to explain their reasoning) }\end{array}$ & $\begin{array}{l}\text { Paper-and-pencil HW (students are } \\
\text { required to explain their reasoning) or } \\
\text { web-based HW in the multiple-choice } \\
\text { format }\end{array}$ & No tutorial-based HW assigned \\
\hline Post-tests & & A part of a course examination & \\
\hline
\end{tabular}


until faced with a contradiction. TAs are encouraged to give students "space" to grapple with inconsistencies on their own. These inconsistencies thus serve as the main motivation for revising ideas.

- Analyze lines of reasoning. Many tutorials include fictitious student dialogs that highlight common conceptual and reasoning difficulties. Students are asked to identify productive and problematic aspects of the presented arguments. This activity provides an explicit opportunity for students to examine multiple reasoning approaches before being confronted with evidence that supports a specific line of reasoning.

- Reflect on changes in thinking. Each tutorial begins with a web-based pretest that students complete before coming to their tutorial section. Pretests are typically given after lecture and lab instruction (but before tutorial instruction). Pretests elicit student thinking about a specific concept or situation, often as the initial step in the elicit-confront-resolve-reflect strategy. Students commit to their answers and provide written explanations. Upon completion of tutorial instruction students are given an opportunity to consider the pre-test questions again and reflect on whether or not their thinking changed during instruction and why. (In the UW implementation, students are encouraged to look at a pretest poster available in the classroom and discuss how, if at all, they would change the explanations they gave initially on the web-based administration of the questions. This activity is not an explicit part of the published tutorial materials.)

\section{B. Interactive lecture implementation}

\section{Review of previous approaches}

Strategies for transforming a large-enrollment, instructorcentered lecture hall to a student-centered environment have been successfully implemented. ${ }^{17}$ Meltzer and Manivannan provide a thorough review of such strategies; ${ }^{18}$ here we briefly describe two approaches most relevant to the present discussion. Peer-instruction, developed by Mazur and colleagues at Harvard University, ${ }^{19}$ employs mini-lectures followed by targeted multiple-choice assessment questions known as ConcepTests. Students first answer individually using "clickers." Then, depending on the prevalence of correct responses, the instructor may provide additional lecture, ask students to discuss their answers with each other and revote, or simply explain the solution to the ConcepTest.

A variant referred to as The Fully Interactive Physics Lectures, developed by Meltzer and Manivannan, aims for a virtually continuous dialog between students and instructors. ${ }^{18}$ In lieu of mini-lectures, students read a set of notes with background information. Class starts with a brief review of relevant concepts, and then moves to sequences of multiple-choice questions. The questions target qualitative reasoning and proceed from simple to more challenging within a given sequence. An instructor obtains response statistics in real time, which informs subsequent questioning. Follow-up activities can include interactive lecture demonstrations, group-work using worksheets, or mini-lectures. The researchers articulated two components critical for successfully transforming a traditional lecture to an interactive learning environment. First, students must be guided in a deliberate manner to think about, discuss, and respond to carefully designed sequences of questions and exercises. Second, there must be a mechanism for the instructor to obtain responses from all students simultaneously. This facilitates formative assessment by allowing instructors to gauge student thinking and adjust instruction accordingly.

\section{Tutorial Implementation in Lecture at NDSU and WWU}

NDSU is a comprehensive, Ph.D.-granting institution, that accepts approximately $85 \%$ of students who apply to the freshman class (see Table III). WWU is a comprehensive, Master's-granting institution, with an acceptance rate of about $80 \%$. The range of SAT math scores for the middle $50 \%$ of students admitted in fall 2011 are comparable for NDSU and WWU (490-620 and 510-610, respectively), somewhat lower than those for the University of Washington $(570-700) .{ }^{10}$ In addition, UW is more selective, with an acceptance rate of less than $60 \%$.

At both NDSU and WWU, tutorials were implemented in an introductory calculus-based physics sequence for science and engineering majors with typical enrollment of about 180 students in a single section at NDSU and about 60 students in each of 3 or 4 lecture sections at WWU. Each course consists of two required components: lecture ( 4 h/week) and laboratory. No recitations are offered at either institution. Two-hour labs at NDSU are fairly traditional. At WWU, most labs include a guided inquiry portion based on Tutorials in Introductory Physics, in which students develop concepts through empirically driven, qualitative investigations. Note that the current study reports not on this lab-based use of the tutorials, but rather on how the tutorials (on the topics not covered in lab) have been used in the lecture environment.

At both institutions, at least one-third of lecture time was spent working through tutorials. Worksheets adapted from Tutorials in Introductory Physics were posted on the course website for students to print out and bring to class. A primary goal was to intellectually engage students in thinking through the logical development of ideas laid out in the published tutorials. While both secondary implementation sites shared this common goal, ways in which the instructors facilitated student engagement with the material differed. Below we outline tutorial-based lecture instruction while highlighting implementation differences at the two institutions (see Tables I and II for a comparison of implementation at UW, NDSU, and WWU).

Before instruction on each topic, students completed a pretest: in web-based format prior to coming to class at NDSU and in paper-and-pencil format in class under exam conditions at WWU. At NDSU, no formal instruction or reading was assigned prior to tutorial instruction. Students were guided to develop specific concepts before formal names and conventions were introduced. For example, in Superposition and reflection of pulses, discussed in detail below, students first predict the behavior of a spring with pulses traveling

Table III. Comparison of student population (admission for fall 2011).

\begin{tabular}{lccc}
\hline \hline & UW & NDSU & WWU \\
\hline $\begin{array}{l}\text { Aggregated SAT math scores } \\
\text { for the middle 50\% }\end{array}$ & $570-700$ & $490-620$ & $510-610$ \\
$\begin{array}{l}\text { Aggregated ACT math scores } \\
\text { for the middle 50\% }\end{array}$ & $25-31$ & $21-26$ & $22-27$ \\
\begin{tabular}{l} 
Percent admitted \\
\hline \hline
\end{tabular}
\end{tabular}


toward each other, then observe the shape of the spring as the pulses pass through one other, and finally develop a rule for "addition" of pulses. Only then is their rule given a name: the principle of superposition. At WWU, tutorials were typically done after assigned reading and after presentation of a lecture overview of the key ideas from the textbook chapter under study. (The lecture overviews sometimes used peer instruction questions to check for class comprehension.)

During discussions in canonical tutorials, it is expected that student thinking patterns will vary and that TAs will tailor their questioning techniques to match the learning needs of a particular group. At NDSU, the tutorials were implemented in a large-enrollment $(\mathrm{N} \sim 180)$ course with no TA support. A decision was thus made not to allocate extended blocks of time (i.e., $>5 \mathrm{~min}$ ) for small group discussion of question sequences. Instead, questions were presented to the class one-by-one using an overhead projector. All students considered a specific question simultaneously, and the instructor solicited explanations. Selected questions, deemed critical for the development of ideas, were presented in a peer instruction format: a set of possible answers were shown to the class, students discussed their reasoning with one another, and submitted responses individually using clickers. Results of the class vote were then revealed, and students were encouraged to support their answers in a whole-class discussion.

Instructor choice of which questions to present in peerinstruction format was informed in part by the structure of the specific sequence of questions under study. Indeed, the UW tutorial developers have placed "check points" throughout the published materials with the purpose of drawing attention to instructional junctures critical for the development of ideas. Peer instruction questions were chosen to best support progress toward the learning targets of a specific sequence. (For more details on practical and intellectual issues relevant to student engagement with the materials, see an online suite of Instructor resources. ${ }^{20}$ ) For example, in Superposition and reflection of pulses, students typically do not require assistance when negotiating the question sequence that develops a rule for the linear superposition of pulses. However, in order to check the more challenging skill of applying the principle of superposition in a specific case, the instructor posed a tutorial question in peer instruction format and encouraged students to discuss their approaches with one another.

Additional guidance for the selection of questions to pose in peer instruction format was provided through active monitoring of student-student and student-instructor interactions. A critical characteristic of any interactive learning environment is instructor ability to rapidly modify instruction based on student feedback. In canonical tutorials, TA-student interactions are intended to be responsive to student thinking. Tutorial-based lecture environments also allow for such flexibility. An instructor may decide in real time to "convert" a specific question in the tutorial sequence to a peer instruction format. This might occur, for example, when classroom conversation reveals diverse patterns in student thinking.

For these reasons, we refrain from providing detailed lesson plans or instructional timelines for the tutorials discussed in this paper. On the contrary, we emphasize that for the published tutorial materials to be implemented successfully in any setting, student-instructor interactions must be authentically responsive to the student ideas that arise during classroom instruction.

Unlike the NDSU implementation, at WWU extended blocks of time were allocated for small group work. Students were asked to work in pairs through the sequenced questions in the worksheet, and to discuss their ideas and check their results together. The instructor circulated during these 7-15 min time periods, listening to student conversations to gauge understanding, and responding to student questions. After calling the students together, the instructor guided a full-class discussion by drawing out specific questions and encouraging other students to respond with their ideas. Sometimes the instructor began these class discussions with a peer instruction question based closely on the preceding segment of tutorial questions. (For example, the class was often asked to vote on which student they agreed with in a hypothetical student dialogue.) Most tutorials involved 3 or 4 alternating periods of small group work and full class discussion. A typical 50-min lecture-based tutorial included 3 or 4 peer instruction questions, somewhat fewer than the 5 or 6 used at NDSU. Much like at UW, at both institutions, students were encouraged to take detailed written notes on their tutorial worksheets during interactive lectures; the worksheets themselves were not collected or graded.

At both institutions, instructors used the pretest questions as an additional opportunity for students to reflect on their learning. At NDSU, selected pretest questions were often presented in class in a peer instruction format at appropriate instructional junctures and students' current understanding was compared to that before tutorial instruction. At WWU, upon completion of a given tutorial, the instructor passed back students' written pretests. Students were asked to collaborate with a neighbor to think through the question(s) again, and then to review their original answers and compare their current and initial ideas. A full class discussion of the pretest was used to close the tutorial sequence.

\section{EVALUATING THE EFFECTIVENESS OF TUTORIAL INSTRUCTION}

To assess the effectiveness of lecture-based tutorial instruction, we have administered written tasks designed to probe specific aspects of student learning. Here, we present examples drawn from two domains: mechanical waves and Galilean relativity. The focus is not on the identification of specific difficulties with the physics content, but rather on a comparison of correct response rates as a means of evaluating the relative effectiveness of the canonical and lecture-based implementations described above. For each domain, we first summarize the sequence of intellectual steps through which the tutorial guides students, and then report assessment results.

\section{A. Linear superposition and reflection of pulses from a boundary}

The tutorial Superposition and Reflection of Pulses guides students through the analysis of pulses traveling on a stretched spring. Specific learning targets include application of the principle of linear superposition to predict the shape of the disturbance as two pulses overlap, and the development of a model for reflection from fixed and free ends. A single tutorial section and a single lecture were dedicated to this tutorial at UW and NDSU, respectively. 


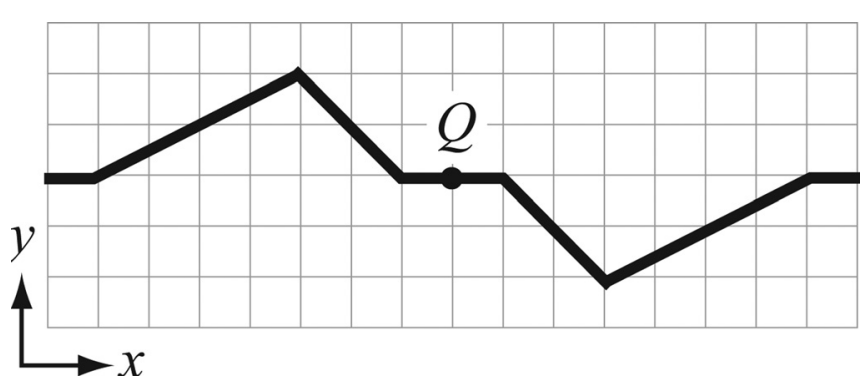

Fig. 1. In Superposition and Reflection of Pulses, students articulate a condition for stationaly point $\mathrm{Q}$ to exist on a spring. A key step in developing the model for reflection is to recognize that point $\mathrm{Q}$ could represent a fixed end of a spring.

\section{Instructional sequence}

Tutorial-based lecture begins by asking students to analyze a sequence of snapshots of two identical pulses traveling toward one another on the same side of the spring. Students are guided to develop a rule for the "addition" of pulses, which is later given the name Principle of Superposition, and practice applying this rule to the case of two asymmetric pulses traveling on the same side of the spring.

To motivate the development of a model for the reflection of pulses from a fixed end, students identify a point that remains stationary as two pulses pass through one another on opposite sides of the spring (i.e., two pulses cause transverse displacements of the spring in opposite directions). Students determine the condition for such a point to exist: the two pulses must be mirror images of each other with respect to both the $x$ - and $y$-axes (see Fig. 1). Using a video of a simple pulse reflecting from a fixed end, a sequence of snapshots included in the tutorial worksheet, and a PhET simulation, ${ }^{21}$ students "observe" that a pulse incident on a fixed end reflects on the opposite side of the spring with roughly unchanged amplitude (maximum transverse displacement) and width. To predict the shape of the spring during reflection, students develop an analogy between (1) the superposition of two pulses for which a stationary point exists, and (2) a single pulse reflecting from the fixed end. A key step in developing the model is to recognize that the stationary point could represent the fixed end of the spring, while the two superposing pulses could represent the incident pulse and its reflection. As a means to satisfy the boundary condition for the fixed end, students imagine that the spring extends beyond the boundary and that a "virtual" pulse travels along the imaginary portion toward the incident pulse (e.g., the left and right pulses in Fig. 1 represent incident and "virtual" pulses). As these pulses reach the boundary, they continue moving in their respective directions, and the superposition of the incident and virtual pulses predicts the shape of the spring during reflection.

Once they have articulated the model, students practice applying it to the case of an asymmetric incident pulse. A similar instructional sequence is used to motivate the development of a model for reflection of pulses from a free end of the spring. The boundary conditions in this case require that a virtual pulse mirrors the incident pulse with respect to the $y$-axis only.

\section{Assessment of student learning}

Here, we present results from four different assessment tasks administered on course exams at NDSU and UW. Tasks 1 and 2 are each designed to target a single concept or idea (the principle of superposition and the knowledge of how the shapes of incident and reflected pulses compare, respectively), while tasks 3 and 4 require multi-step reasoning in which superposition is applied to determine the shape of the spring during the process of reflection.

a. Task 1: Superposition. Description. Students consider two pulses traveling toward one another on a stretched spring. Students are shown the shape of pulse 1 and the shape of the disturbance observed on the spring at an instant when the pulses overlap as shown in Fig. 2. Students are asked to determine the shape of pulse 2 .

Results. After tutorial instruction, more than $80 \%$ of the students at NDSU and UW provided correct sketches (see Table IV). A similar task, in which students were asked to sketch the shape of the spring when the two asymmetric pulses shown in Fig. 3 completely overlap, has been administered at both institutions as an ungraded, web-based pretest. In this case, only about $10 \%$ of students at each institution were able to determine the correct shape of the spring (see Table IV). These results demonstrate large and comparable gains in student performance across the two populations [two-tailed $p$-value of 0.6 (Ref. 22)], independent of the instructional format in which the tutorials were used.

b. Task 2: Reflection of a simple pulse. Description. This question evaluates the extent to which students can apply a model for reflection. Students are shown the shape of a

A pulse (pulse 1) moves to the right along a spring, as shown below left. Another pulse (pulse 2, not shown) moves in the opposite direction along the same spring. The diagram below right shows the location of pulse 1 (dashed line) and the shape of the spring (shaded line) at an instant while the two pulses meet. On the diagram below right, draw the shape and location of pulse 2 at the instant shown.
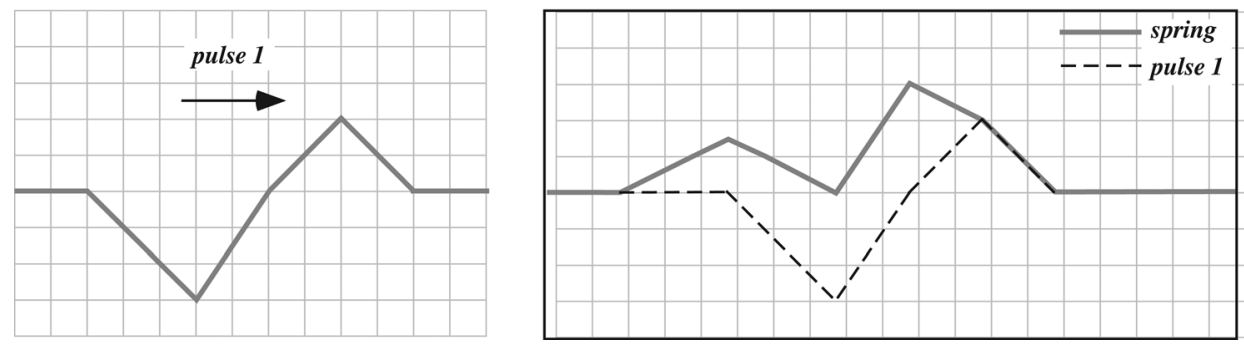

Fig. 2. Task 1: Superposition. 
Table IV. Comparison of student performance on pre- and post-test tasks on the topic of superposition and reflection of pulses at NDSU and UW.

\begin{tabular}{|c|c|c|c|c|c|c|}
\hline \multirow[b]{2}{*}{ Assessment } & \multicolumn{2}{|c|}{ Total number of students } & \multirow[b]{2}{*}{ Response } & \multicolumn{2}{|c|}{ Percentage of student responses } & \multirow[b]{2}{*}{ Two-tailed $p$-value } \\
\hline & NDSU & UW & & NDSU & UW & \\
\hline \multicolumn{7}{|c|}{ Task 1. Superposition } \\
\hline Post-test & 175 & 193 & Correct & $83 \%$ & $81 \%$ & 0.6 \\
\hline Pre-test & 314 & 2660 & Correct & $12 \%$ & $11 \%$ & 0.6 \\
\hline \multicolumn{7}{|c|}{ Task 2: Reflection of a simple pulse } \\
\hline & & & Correct & $60 \%$ & $76 \%$ & 0.01 \\
\hline \multirow[t]{2}{*}{ Post-test } & 175 & 193 & Incorrect leading edge & $31 \%$ & $19 \%$ & 0.01 \\
\hline & & & Incorrect orientation & $8 \%$ & $4 \%$ & 0.12 \\
\hline Pre-test & $\mathrm{N} / \mathrm{A}$ & 1008 & Correct & $\mathrm{N} / \mathrm{A}$ & $15 \%$ & N/A \\
\hline \multicolumn{7}{|c|}{ Tasks 3 and 4: Reflection of a complex pulse } \\
\hline $\begin{array}{l}\text { Post-test: Shape of the spring } \\
\text { at a specific instant in time }\end{array}$ & 101 & 153 & Correct with correct reasoning & $89 \%$ & $92 \%$ & 0.4 \\
\hline \multirow{3}{*}{$\begin{array}{l}\text { Post-test: Changes in the } \\
\text { shape of the spring over } \\
\text { interval of time }\end{array}$} & 175 & 193 & Correct with correct reasoning & $51 \%$ & $48 \%$ & 0.6 \\
\hline & & & $\begin{array}{c}\text { Memorization of outcomes of } \\
\text { simple-pulse reflection experiments }\end{array}$ & $15 \%$ & $9 \%$ & 0.07 \\
\hline & & & $\begin{array}{l}\text { Attempt to apply reflection models; } \\
\text { failure to apply superposition principle in } \\
\text { fixed-end case (free end is correct) }\end{array}$ & $5 \%$ & $11 \%$ & 0.02 \\
\hline
\end{tabular}

spring after a simple asymmetric pulse has reflected from a boundary, and are asked to sketch the shape at an instant before the pulse reached the boundary (see Fig. 4). Students consider each of two cases: fixed-end and free-end reflections. In a correct response for the free-end reflection, the incident and reflected pulses must have the same orientation; for the fixed-end reflection, opposite orientations. In both cases, the leading edges and the shapes of the incident and reflected pulses must be the same.

Results. After tutorial instruction, the fraction of students sketching the correct shape of the incident pulses for both the free and fixed end cases was $60 \%$ at NDSU and $76 \%$ at UW. Most students who failed to provide correct sketches drew the leading edge of the incident pulse incorrectly. Fewer than $10 \%$ of NDSU students and 5\% of UW students sketched incident pulses with incorrect orientations (see Table IV).

A similar task, shown in Fig. 5, was administered at UW as a written pretest question in paper-based format. Only $\sim 15 \%$ of students correctly sketched the reflected pulse when presented with a simple pulse of asymmetric, triangular shape incident on a fixed end. We judge this task, which involves reasoning "forward" from the incident pulse to the reflected pulse, to be comparable in difficulty with, or even somewhat easier than task 2. The forward-reasoning task has not been given as a pretest at NDSU. However, in all examined cases, spanning diverse contexts, NDSU student pretest performance has been comparable to that at UW. ${ }^{8,23}$ We thus expect that NDSU students would perform similarly to the students at UW on the reflection pretest. On the pretest, almost half of the UW students sketched a reflected pulse with the same orientation as the incident pulse, while the remaining responses were unclear or blank.

Commentary. These results suggest that the lecture-based implementation of the tutorial at NDSU was successful in helping most students develop a model for reflection from a boundary. We speculate that the difference in correct response rates (two-tailed $\mathrm{p}<0.01$ ) may be due to additional homework practice opportunities available to UW students upon completion of the Reflection and Transmission tutorial. (UW Students completed the Reflection tutorial and associated HW before the exam containing the discussed task was given.) This tutorial follows Superposition and Reflection and focuses on the behavior of pulses at a boundary between two media (e.g., two springs connected at a junction). In the homework, UW students practiced sketching the shapes of the springs after a simple triangular pulse has reached the junction between them. These exercises required qualitatively correct sketches of the incident, reflected, and transmitted pulses (including orientation, width, leading edge, and distance from the boundary) based on given information. Although the Reflection and Transmission tutorial was implemented at NDSU in lecture-based format, these exercises were not assigned as HW due to the lack of TA support for grading.

c. Tasks 3 and 4: Reflection of a complex pulse. Tasks 3 and 4 assess student ability to apply their models for reflection in the context of a sequence of two simple pulses that cause displacements of the coils on opposite sides of the spring (see Figs. 6 and 7). We refer to such a sequence of

Shown at right is a "snapshot" of a spring with two identical pulses traveling along it. (The size and shape of the pulses are exaggerated for clarity.) Each pulse moves with a speed of $4 \mathrm{~m} / \mathrm{s}$, and the pulses are moving toward each other.

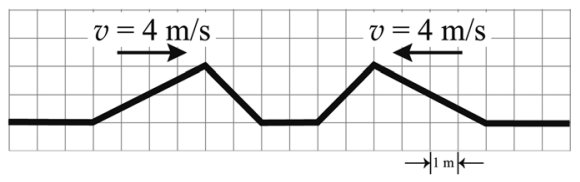

Sketch the shape of the spring one second after the snapshot above was taken. Explain in words how you made your prediction.

Fig. 3. Variation of Task 1 (used as Superposition pre-test). 
A pulse was moving to the right toward a boundary. The diagram shows the reflected pulse, which is moving left. On the grids provided, draw the incident pulse at an instant before it reaches the end of the spring in the case in which the end is (1) fixed or (2) free. No explanation is necessary.

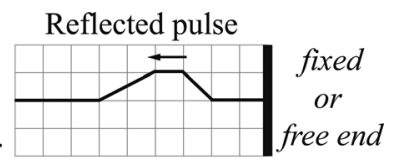

(1) incident pulse if end is fixed

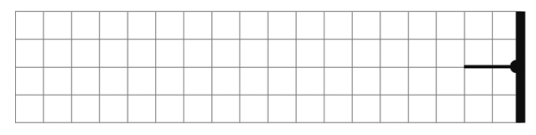

(2) incident pulse if end is free

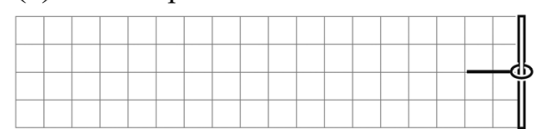

Fig. 4. Task 2: Reflection of a simple pulse.

simple pulses as a complex pulse. In Task 3 the students must determine the shape of the spring at a specific instant in time during the reflection. In Task 4 students analyze changes in the shape of the spring that occur over the interval during which a complex pulse reflects from a boundary, a skill critical for the understanding of standing waves.

Description of Task 3. A complex pulse is incident on an end of a spring with a speed of $1 \mathrm{~m} / \mathrm{s}$ as shown in Fig. 6. The shape of the spring $\Delta \mathrm{t}=0.8 \mathrm{~s}$ later is also shown. Students are asked to determine whether the end of the spring is fixed or free.

Results. Almost all students $(\sim 90 \%)$ recognized that the maximum transverse displacement of a spring increases when two pulses overlap on the same side. Therefore, the incident and already reflected portions of the pulse must overlap on the same side, and the end of the spring must be fixed.

Description of Task 4. Students consider a complex pulse incident on an end of a spring, with a small cup placed near the end as shown in Fig. 7. The task has two parts: students must decide whether the cup will be knocked in the case of a fixed-end reflection and then in the case of a free-end reflection. To answer correctly, students can recognize that (1) for the cup to be knocked over, the transverse displacement D of a point on the spring must be at least 2.5 units in the direction of the cup, (2) for a displacement $\mathrm{D} \geq 2.5$ units to occur, the trailing portion of the pulse must overlap constructively with a reflected portion, (3) for the fixed-end case: $D_{\max }=3$ units when the leading portion of the pulse reflects on the opposite side of the spring and overlaps with the trailing portion, and (4) for the free-end case: $D_{\max }=2$ units when the trailing portion of the pulse reflects and overlaps with itself. These steps involve applying the model for reflection, visualizing propagation of reflected and incident portions of the pulse, and using the principle of superposition. Task 4 thus involves greater synthesis of concepts and more steps in reasoning than tasks 1 and 2 , or even task 3 .

Results. After tutorial instruction, half of each student population answered both questions correctly (see Table IV). The types and prevalence of common incorrect reasoning was also consistent. About $15 \%$ of NDSU and $10 \%$ of UW students seemed to inappropriately generalize the outcomes of experiments involving reflection of simple pulses from fixed and free ends. Instead of applying the reflection model to the complex pulse presented, these students argued that (1) for the fixed end, $D_{\max }$ never exceeds the amplitude of an incident pulse, and (2) for the free end, $\mathrm{D}_{\max }$ increases and the spring knocks over the cup. Other students $(\sim 5 \%$ of NDSU and $\sim 10 \%$ of UW students) answered correctly for the free-end case but incorrectly for the fixed-end. For the latter, these students correctly stated that the leading portion of the pulse reflects on the opposite side of the spring but failed to apply the principle of superposition to the two overlapping portions, concluding that the amplitude of the leading portion is not large enough to knock over the cup.

Commentary. Differences in student performance on tasks 3 and 4 (and tasks similar to those) have been discussed in detail elsewhere. ${ }^{24}$ We identified four critical features of the questions that could account for the difference in correct response rates. However, we believe that the less satisfactory student performance on task 4 is more likely due to difficulties in visualizing and reasoning spatially about changes in the shape of the spring that occur over an interval of time. Task 3 requires students to determine the shape of the spring at a specific instant (e.g., $y(x)$ at time t), while on task 4 students must consider changes in the transverse displacement of a point on the spring over a time interval (e.g., $\mathrm{y}(\mathrm{t})$ for a specific $\mathrm{x})$. Preliminary results suggest that indeed there is a significant relationship between performance on these two post-tests and ability to reason spatially, as measured by a paper-folding test. ${ }^{25}$

In summary, results from the assessment tasks above suggest that the NDSU and UW students had comparable abilities to analyze the behavior of pulses propagating on springs both before and after tutorial instruction, regardless of whether the tutorial was implemented in the canonical fashion or in the modified, lecture-based manner described above.

\section{B. Relative motion in one dimension}

The tutorial Relative Motion was designed to guide students to a functional understanding of the concepts of relative velocity and relative displacement. The tutorial was done during a single tutorial session and a single lecture at UW and WWU, respectively.

Suppose that one end of the spring were fastened to a wall so that it could not move, as shown. An asymmetric pulse moves toward this end of the spring at a speed of $3 \mathrm{~m} / \mathrm{s}$.

Sketch the shape of the spring two seconds after the snapshot above was taken. Explain in words how you made your prediction.

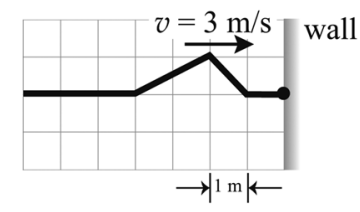

Fig. 5. Reflection pretest. 
A pulse moves toward one end of a spring at a speed of $1 \mathrm{~m} / \mathrm{s}$. It is not known whether the end of the spring is fixed to the rod shown or is free to slide along it.

The diagrams at right show the shape of the spring at $\boldsymbol{t}=0.0 \mathrm{~s}$ and at $\boldsymbol{t}=0.8 \mathrm{~s}$.

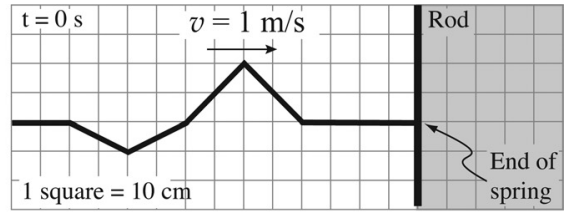

i. Is the end of the spring fixed or free? Explain your reasoning in detail.

ii. Sketch the shape of the spring at $\boldsymbol{t}=\mathbf{1 . 6} \mathrm{s}$.

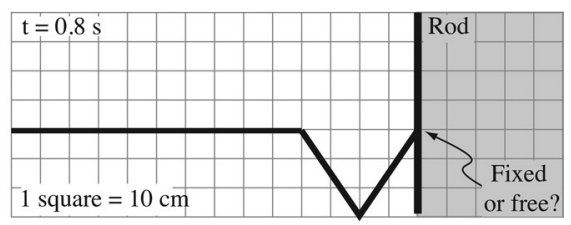

Fig. 6. Task 3: Reflection of a complex pulse.

\section{Instructional sequence}

The tutorial begins by using the context of the Spaceships task (see section b below for a description) to guide students through the steps needed to apply an operational definition of displacement in a frame moving relative to the laboratory. ${ }^{26}$ Students construct a representation, referred to as an Event diagram in the literature on physics pedagogy, ${ }^{27}$ that shows an object of interest (the "shuttle craft") at an initial and final time as viewed by an observer moving relative to the laboratory. Students then use the diagram to draw vectors for the initial position, final position, and change in position of the shuttle in the "moving" frame. Students repeat this process for a second frame (also moving relative to the laboratory), and are guided to recognize that the magnitude and direction of the change in position vector depends on the frame in which it is measured. The tutorial includes questions that target specific difficulties identified through research (e.g., the tendency to confuse position and change in position).

Students are then guided to transfer the ideas described above to a situation involving two vehicles that move along a straight road. In this part of the tutorial, students construct relative velocity vectors, and are guided to recognize that whether an object is speeding up or slowing down can depend on the reference frame in which the motion is measured. The tendency to confuse relative position and relative velocity (a tendency that is especially strong for cases in which one object is passing another) is addressed explicitly.

\section{Assessment of student learning}

A variety of written tasks have been developed and administered to gauge student learning of Galilean relativity. Here, we present results from two such tasks as evidence of the effectiveness of tutorial instruction. The first targets the concept of relative velocity, the second, relative displacement. Note that none of the students in this study received the same question more than once. If a specific question was used as both a pre- and a post-test, it was given to different cohorts of students (i.e., different course sections).

a. Task 5: Relative velocity (Trooper question). Description. In the Trooper question, shown in Fig. 8, students consider two cars moving in the same direction along a straight road. The first, referred to as "the speeder," has initial speed $0.8 v_{0}$ at time $t=0 \mathrm{~s}$ and slows down at a constant rate to a final speed of $0.4 v_{0}$ at time $t=4 \mathrm{~s}$. The second car, referred to as "the trooper," moves with constant speed $v_{0}$. Students are told that the speeder is located ahead, or in front of the trooper during the entire four-second interval under consideration.

In part $\mathrm{A}$ of the question, students are asked to determine qualitatively the motion of the speeder's car in the trooper's frame. Students select from three options: speeding up, slowing down, or motion with constant speed. To answer correctly, students can first recognize that since the ground frame velocity of the speeder has smaller magnitude than that of the trooper, the speeder is approaching the trooper. Furthermore, because the speeder is slowing down in the ground frame, the difference between the speeder's velocity and the trooper's velocity is increasing, and the speeder is approaching the trooper at an increasing rate. Therefore, the speeder's car is speeding up in the frame of the trooper.

In part B, students are told that the trooper uses a "laser ranging device" to find that the distance between the two cars is $50 \mathrm{~m}$ at time $t=2 \mathrm{~s}$ and $40 \mathrm{~m}$ at time $t=3 \mathrm{~s}$. Students are asked whether the distance between the cars will be greater than, less than, or equal to $30 \mathrm{~m}$ at time $t=4 \mathrm{~s}$. To answer, students can work in either the trooper's frame or the ground frame. For the former, students can apply their answer from the first part of the question: since the speeder approaches the trooper at an increasing rate, the separation distance must change by a greater amount in the later onesecond time interval, and the distance between the cars will be less than $30 \mathrm{~m}$ at time $t=4 \mathrm{~s}$. A ground frame analysis proceeds by comparing the average speeds of the trooper and

A pulse moves toward the right end of the spring. The top view diagram at right shows the shape of the spring at $t=0 \mathrm{~s}$. A cup is placed near the right end of the spring as shown.

Is it possible for the cup to be knocked over? If so, must the end of the spring be fixed or free? Explain your reasoning.

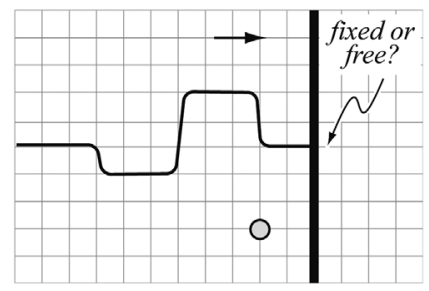

Fig. 7. Task 4: Reflection of a complex pulse with a cup. 
A trooper drives her car with constant speed $v_{0}$ to the east along a straight road. A speeder drives his car to the east on the same road while slowing down at a constant rate. The speeder moves at $0.8 v_{0}$ at time $t=0 \mathrm{~s}$, and $0.4 v_{0}$ at time $t=4 \mathrm{~s}$. For the entire interval from $t=0 \mathrm{~s}$ to $t=4 \mathrm{~s}$, the speeder is ahead of the trooper (i.e., the speeder is located to the east of the trooper).

1. In the reference frame of the trooper, is the speeder's car speeding up, slowing down, or moving with constant speed at $t=2 \mathrm{~s}$ ? Explain.

2. The trooper has a laser ranging device that can determine the distance between the two cars. She finds that the distance is 50 meters at $t=2 \mathrm{~s}$ and 40 meters at $t=3 \mathrm{~s}$. At $t=4 \mathrm{~s}$, will the distance be greater than, less than, or equal to 30 meters? Explain.

Fig. 8. Task 5: Relative velocity (Trooper question).

speeder. Since the speeder travels more slowly, it covers less distance than the trooper for each one-second interval. Since the speeder's car is slowing down, this differential in distance traveled is increasing over subsequent one-second intervals, and the separation distance between the two cars will be less than $30 \mathrm{~m}$ at time $t=4 \mathrm{~s}$.

Administration. At WWU, the Trooper question has been given in one section of the introductory course as an in-class written pretest prior to instruction in relative motion. It has also been administered on an exam in a different course section, after students had received all instruction in kinematics, including the relative motion tutorial. Students completed the tutorial as an interactive lecture, in the manner described above. At UW, the task was administered as a web-based pretest, prior to instruction on relative motion, in multiple lecture sections, and as a post-test on a course exam to a different cohort of students, after those students had completed the relative motion tutorial in the canonical manner.

Results. Findings suggest that introductory physics students at both institutions experienced considerable difficulty with part A of the Trooper question prior to tutorial instruction: only $12 \%$ of WWU students and $10 \%$ of UW students answered correctly on the pretest (see Table V). At each university, the most common incorrect answer was that the speeder is slowing down in the trooper's frame. In their written explanations, many students failed to distinguish the two frames, or indicated that the trooper could "figure out" from observing the speeder's car that it "must be slowing down". The correct response rates on the exam, given after tutorial instruction, were much higher: $72 \%$ at WWU and $60 \%$ at UW.

On part B, involving the laser ranging device, $48 \%$ of WWU students and $35 \%$ of UW students reached the correct answer on the pretest. In each case, the most common incorrect response was that the separation between the cars would be equal to 30 meters at time $t=4 \mathrm{~s}$. (This response is consistent with an incorrect assumption of a uniform relative velocity of the trooper and the speeder, suggesting confusion between the concepts of velocity and acceleration.) Exam results at the two universities were similar, with a correct response rate of $63 \%$ at WWU and $55 \%$ at UW.

Commentary. Comparison of pretest and exam performance on the Trooper question suggests comparable gains in understanding of the concept of relative velocity in each of the two student populations (UW and WWU), despite the differences in the format of tutorial instruction. Gains in performance were substantial on part $\mathrm{A}$ of the question, and more modest on part B. Part A asks explicitly about a frame moving relative to the laboratory and is thus tightly linked to the reasoning developed in the tutorial, while part B asks about frame invariant quantities and can be solved by working either in the moving frame or in the lab frame. The smaller gains on part B are consistent with the greater amount of transfer required for this task.

\section{b. Task 6: Relative displacement (Spaceships} question). Research on student understanding of relative velocity led to development of the Spaceships question, a task designed to probe functional understanding of the underlying concept of change in relative position.

Description. This task, shown in Fig. 9, involves two spaceships, A and B, that move towards one another while a third, the "shuttle," travels from one to the other. A and B move along a straight-line path from an initial separation distance $d_{i}$ to a final separation $\mathrm{d}_{\mathrm{f}}\left(d_{f}<d_{i}\right)$. The shuttle starts the interval with the same position as spaceship A and ends with the same position as B. Students are asked to rank the magnitudes of the following quantities: $d_{\mathrm{i}}, d_{\mathrm{f}}, \Delta \boldsymbol{x}_{\mathrm{s}, \mathrm{A}}$ and $\Delta x_{\mathrm{s}, \mathrm{B}} . \Delta x_{\mathrm{s}, \mathrm{A}}$ refers to the change in position of the shuttle from the initial to the final time as measured in the frame of spaceship A, while $\Delta \boldsymbol{x}_{\mathrm{s}, \mathrm{B}}$ refers to the frame of B. When considering the shuttle's displacement in the frame of spaceship A, students can treat spaceship A as stationary. The shuttle

Table V. Comparison of student performance on pre- and post-test tasks on the topic of relative motion at WWU and UW.

\begin{tabular}{|c|c|c|c|c|c|c|}
\hline \multirow[b]{2}{*}{ Assessment } & \multicolumn{2}{|c|}{ Total number of students } & \multirow[b]{2}{*}{ Response } & \multicolumn{2}{|c|}{ Percentage of student responses } & \multirow[b]{2}{*}{ Two-tailed $p$-value } \\
\hline & WWU & UW & & WWU & UW & \\
\hline \multicolumn{7}{|c|}{ Task 5. Relative velocity (Trooper question) } \\
\hline \multirow[t]{2}{*}{ Post-test } & 67 & 344 & Correct on part A & $72 \%$ & $60 \%$ & 0.06 \\
\hline & & & Correct on part B & $63 \%$ & $55 \%$ & 0.2 \\
\hline \multirow[t]{2}{*}{ Pre-test } & 57 & 246 & Correct on part A & $12 \%$ & $10 \%$ & 0.65 \\
\hline & & & Correct on part B & $48 \%$ & $35 \%$ & 0.07 \\
\hline \multicolumn{7}{|c|}{ Task 6: Relative displacement } \\
\hline Post-test: Frisbee at WWU and Butterfly at UW & 67 & 30 & Correct & $27 \%$ & $35 \%$ & 0.4 \\
\hline Pre-test: Spaceship & 53 & 531 & Correct & $5 \%$ & $5 \%$ & 0.97 \\
\hline
\end{tabular}


Spaceships A and B move directly toward one another. The distance between them is $d_{\mathrm{i}}$ at time $t_{\mathrm{i}}$ and $d_{\mathrm{f}}$ at time $t_{\mathrm{f}}$. A shuttle leaves $\mathrm{A}$ at $t_{\mathrm{i}}$ and arrives at B at $t_{\mathrm{f}}$. Rank $d_{\mathrm{i}}, d_{\mathrm{f}}$, $\Delta \boldsymbol{x}_{\mathrm{s}, \mathrm{A}}$ (the change in position of the shuttle relative to $A$ ), and $\Delta x_{\mathrm{s}, \mathrm{B}}$ (the change in position of the shuttle relative to $\mathrm{B}$ ) according to magnitude, from greatest to smallest. Explain.

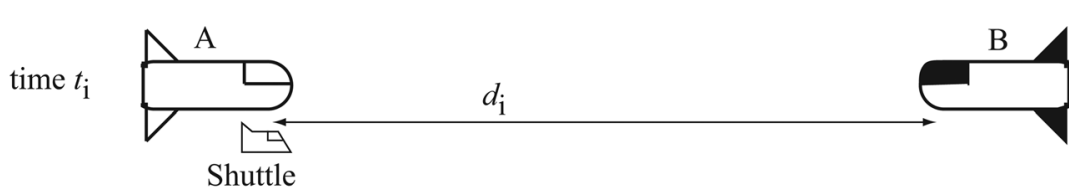

time $t_{\mathrm{f}}$

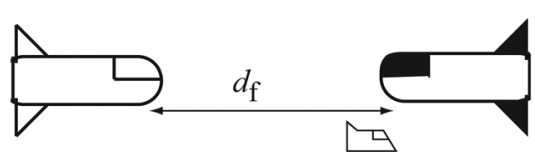

Fig. 9. Task 6: Relative displacement (Spaceships question).

was initially a distance of zero away from A, and later a distance $d_{\mathrm{f}}$. Applying the definition of displacement yields $\left|\Delta x_{\mathrm{s}, \mathrm{A}}\right|=d_{\mathrm{f}}$. A similar analysis in the frame of $\mathrm{B}$ yields $\left|\Delta x_{\mathrm{s}, \mathrm{B}}\right|=d_{\mathrm{i}}$, leading to the correct ranking $\Delta x_{\mathrm{s}, \mathrm{B}}=d_{\mathrm{i}}>d_{\mathrm{f}}=$ $\Delta x_{\mathrm{s}, \mathrm{A}}$.

Two other versions of this question were administered, and require students to apply the reasoning summarized above in slightly different situations. One version involves a frisbee thrown by a student riding in the back of a bus to a second student who is walking in a direction anti-parallel to the velocity of the bus. The other involves a van and a car driving in opposite directions along a straight road, and a butterfly that flies from one to the other. In both versions, there are two "moving" frames moving in opposite directions as measured in an Earth-fixed frame, and students must rank the four quantities analogous to $d_{\mathrm{i}}, d_{\mathrm{f}}, \Delta x_{\mathrm{s}, \mathrm{A}}$ and $\Delta x_{\mathrm{s}, \mathrm{B}}$ described above. (In the variations, the frisbee or the butterfly takes the place of the shuttlecraft.)

Administration. At WWU, the Spaceships and Frisbee versions were given as a pretest and a post-test, respectively, in different course sections. At UW, the Spaceships question was given in multiple sections as an online pretest. Before taking the pretest, students received varying amounts of traditional instruction in relative motion, ranging from no prior instruction to a standard lecture presentation of the Galilean transformation of velocities. Results from the different sections were similar and have been grouped. The Butterfly version was given at UW on a course exam after canonical implementation of the tutorial.

Results. As with the Trooper question, student pretest performance was similar at WWU and UW: in each case, only about $5 \%$ of students ranked the four quantities correctly on the pretest. Most students had difficulty recognizing that the displacement of the shuttle in the frame of spaceship A is equal to the final distance between the spaceships. Correct response rates were higher on the exam: $27 \%$ of students at WWU completed the Frisbee version correctly after lecturebased tutorial instruction, while $35 \%$ of UW students completed the Butterfly question correctly after canonical tutorial instruction.

Commentary. Clearly the Spaceships task and its variations present substantial difficulty for introductory students, even after instruction. As with the relative velocity task (the Trooper question), however, results from the Spaceships task indicate that learning gains were comparable whether students received tutorial instruction in the canonical format, at UW, or in the modified, lecture-based format, at WWU.

\section{DISCUSSION}

Data presented above, together with assessment data from other tutorials that we have adapted, ${ }^{8,23}$ suggest that the examined materials from Tutorials in Introductory Physics are flexible enough to support student learning in instructional environments different from those suggested by the curriculum developers. The details of the curricular implementation differed in many ways, while student active engagement with the materials themselves was common to all three implementation sites. We thus argue that comparable learning gains are linked to student engagement with the intellectual substance of the tutorial, and that not all aspects of the canonical implementation are required to support learning. In particular, our implementation replaced the small group discussions and low student-instructor ratio of canonical tutorials with a single instructor working with many students in a lecture hall not designed for group work. Furthermore, variations in the specific methods used by the instructor in engaging students did not seem to impact learning gains.

We recognize limitations in our findings. Both instructors in this study have a background in physics education research (PER) with a specific focus on student understanding of waves $(\mathrm{MK})$ and Galilean relativity $(\mathrm{AB})$. Both instructors were deeply involved in the research that led to the development and refinement of the tutorial materials on these topics. Both have considerable experience teaching tutorials in the canonical format. As such, it may be argued that this study examined the extent to which the tutorials are effective in lecture-based format when implemented under highly favorable conditions. Based on our experience with the UW TA preparation model, however, we are optimistic that non-PER instructors who possess sufficient pedagogical content knowledge would be able to reproduce results achieved in this study. ${ }^{28}$ Indeed, most UW tutorial sessions are led by non-PER graduate and undergraduate students. Most of these students are first year TAs with no prior teaching experience or formal knowledge of pedagogy. Despite these limiting factors, a weekly seminar designed by the UW Physics Education Group seems to prepare first-year TAs to teach tutorials effectively. During the seminar, TAs work through an upcoming tutorial, review student responses to pretest questions, and briefly identify specific tutorial activities that address observed student difficulties. We expect that any instructor interested in adopting tutorial materials would recognize the need to adequately prepare in a similar manner. The next phase of this project will therefore examine whether or not instructor expertise in PER is a necessary condition for achieving comparable gains in the two implementation modes.

In addition to instructor effects, the nature of the tutorial topics themselves bears consideration when evaluating the results. The mechanical waves tutorial guides students to develop a model based on their own observations of the behavior of pulses on springs, and does not require significant 
prior knowledge of physics concepts. The relative motion tutorial focuses on the development of the procedures needed to operationalize the concepts of displacement and velocity. It may be that tutorials of this nature (i.e., those that center on developing empirical models or operational definitions) are more amenable to lecture-based implementation. The UW tutorial Light and Shadow also fits these characteristics. Students build a ray model for light on the basis of observations made with pinholes and screens. Preliminary analysis of assessment data suggests comparable gains in student ability to apply their models after lecture-based use of the tutorial at NDSU and canonical use of the tutorial at UW. ${ }^{29}$

Finally, implementation of tutorials by a lecture professor during the lecture period may enhance the coherence of the course for students, thus improving their overall learning experience. During the parts of the lecture not used for tutorial instruction, the instructors at NDSU and WWU (MK and $\mathrm{AB}$ ) referred back to the ideas students had developed during tutorial. At UW, on the other hand, different instructors are assigned to the lecture and tutorial components of the course. As such, lecture instructors rarely draw on the tutorial materials $^{30}$ therefore resulting in the loss in coherence.

\section{CONCLUSION}

This study contributes to a growing research base on the evaluation of secondary implementations of instructional innovations. Comparable gains in student understanding were achieved when UW tutorials on mechanical waves and Galilean relativity were adapted for classroom conditions significantly different from those suggested by the tutorial developers. Features of the canonical UW tutorials, such as a low student to instructor ratio, self-paced work in small groups, and instructor feedback tailored to individual students could not be implemented in the instructional environment at NDSU and WWU. Results of this study demonstrate that it is possible to implement PER-based materials in a manner that fits specific institutional constraints and achieves student performance comparable to that reported by the developers. It appears that student engagement with the intellectual steps laid out in the tutorials, rather than the specific strategies used in facilitating such engagement, plays the central role in promoting student learning. However, variables such as instructor effects and the specific tutorial topic may limit generalizability. We present this study as a demonstration that, under certain conditions, use of tutorials in a large-lecture environment can yield learning gains comparable to those seen in the canonical implementation. It is hoped that further research will identify the minimum resources and critical components for effective and sustainable implementation of research-based materials under a broad range of institutional conditions.

\section{ACKNOWLEDGMENTS}

The authors wish to thank Paula R. L. Heron and MacKenzie R. Stetzer for valuable discussions related to this work.

\footnotetext{
${ }^{1}$ For example, see C. Henderson, "Promoting instructional change in new faculty: An evaluation of the physics and astronomy new faculty workshop," Am. J. Phys. 76, 179-187 (2008).

${ }^{2}$ M. Dancy and C. Henderson, "Pedagogical practices and instructional change of physics faculty," Am. J. Phys. 78, 1056-1063 (2010).
}

${ }^{3}$ C. Henderson, M. Dancy, and M. Niewiadomska-Bugaj, "Use of researchbased instructional strategies: Where do faculty leave the innovationdecision process?," Phys. Rev. ST Phys. Educ. Res. 8, 020104 (2012).

${ }^{4} \mathrm{C}$. Henderson, "The challenges of change in instructional practices under the best circumstances: A case study of one college physics instructor," Am. J. Phys. 73, 778-786 (2005).

${ }^{5}$ Lillian C. McDermott, Peter S. Shaffer, and the PEG at UW, Tutorials in Introductory Physics, 1st ed. (Pearson/Prentice-Hall, Upper Saddle River, NJ, 2002).

${ }^{6}$ N. Finkelstein and S. Pollock, "Replicating and understanding successful innovations: Implementing tutorials in introductory physics," Phys. Rev. ST Phys. Educ. Res. 1, 010101 (2005); S. Pollock and N. Finkelstein, "Sustaining educational reforms in introductory physics," Phys. Rev. ST Phys. Educ. Res. 4, 010110 (2008).

${ }^{7}$ K. M. Koenig, R. J. Endorf, and G .A. Braun, "Effectiveness of different tutorial recitation teaching methods and its implications for TA training," Phys. Rev. ST Phys. Educ. Res. 3, 010104 (2007).

${ }^{8}$ Other results are reported in: M. Kryjevskaia, M. R. Stetzer, and P. R. L. Heron, "Student difficulties measuring distance in terms of a wavelength: Lack of basic skills or failure to transfer?," Phys. Rev. ST Phys. Educ. Res. 9, 010106 (2013).

${ }^{9}$ See, for example, D. Trowbridge and L. McDermott, "Investigation of student understanding of the concept of velocity in one dimension," Am. J. Phys. 48 (12), 1020-1028 (1980); also see citation 29.

${ }^{10}$ National Center for Education Statistics, U.S. Department of Education, $<$ http://nces.ed.gov/globallocator/>.

${ }^{11}$ For discussion of the development of this tutorial, see T. O'Brien-Pride, S. Vokos, and L. C. McDermott, "The Challenge of matching learning assessments to teaching goals: An example from the work-energy and impulse-momentum theorems," Am. J. Phys. 66, 147-157 (1998).

${ }^{12}$ Paula R. L. Heron, Michael E. Loverude, P. S. Shaffer, and L. C. McDermott, "Helping students develop an understanding of Archimedes' principle. II. Development of research-based instructional materials," Am. J. Phys. 71, 1188-1195 (2003).

${ }^{13}$ L. C. McDermott and the Physics Education Group at the University of Washington, Physics by Inquiry (Wiley, NY, 1996).

${ }^{14}$ R. E. Scherr, "An implementation of Physics by Inquiry in a large enrollment class," Phys. Teach. 41(2), 113-118 (2003). For other discussion of non-canonical implementation of PbI materials see L. C. McDermott, L. K. Piternick, and M. L. Rosenquist, "Helping minority students succeed in science, Part I. Development of a curriculum in physics and biology," J. Coll. Sci. Teach. 9, 136-140 (1980).

${ }^{15}$ The definition of the term understanding shared by the UW PEG researchers (and the authors) is articulated by Heron (see citation 16) as follows: "a student will be considered to understand a topic if, when faced with an unfamiliar problem, he or she reliably selects the appropriate concepts and principles, applies them correctly, and constructs a logically sound solution. Accordingly, instruction will be considered to be improved if more students do this more frequently. (It must be emphasized that his criterion includes not only what the student is capable of doing, but what he or she actually does.)"

${ }^{16} \mathrm{P}$. Heron, Empirical Investigation of Student Learning and Teaching, Part I: Examining and Interpreting Student Thinking, edited by E. Redish and M. Vicentini Proceedings of the International School of Physics "Enrico Fermi" Course CLVI (IOS Press, 2003), vol. 156, pp. 341-365.

${ }^{17}$ David E. Meltzer and Ronald K. Thornton, "Resource Letter ALIP-1: Active-Learning Instruction in Physics,” Am. J. Phys. 80(6), 478-496 (2012).

${ }^{18}$ D. E. Meltzer and K. Manivannan, "Transforming the lecture-hall environment: The fully interactive physics lecture," Am. J. Phys. 70, 639-654 (2002).

${ }^{19}$ Crouch C. H. and E. Mazur, "Peer Instruction: Ten years of experience and results," Am. J. Phys. 69(9), 970-977 (2001).

${ }^{20}$ For an online suite of Instructor Resources see $<\mathrm{http}$ ://courses. washington.edu/uwpeg/>.

${ }^{21}$ Link to simulations <http://phet.colorado.edu/>. Also see N. D. Finkelstein, W. K. Adams, C. J. Keller, P. B. Kohl, K. K. Perkins, N. S. Podolefsky, S. Reid, R. LeMaster, "When learning about the real world is better done virtually: A study of substituting computer simulations for laboratory equipment," Phys. Rev. ST Phys. Educ. Res. 1(1), 010103 (2006); Carl E. Wieman, Katherine K. Perkins, and Wendy K. Adams "Oersted Medal Lecture 2007: Interactive simulations for teaching physics: What works, what doesn't, and why," Am. J. Phys. 76, 393-399 (2008).

${ }^{22}$ The two-tailed p-value is calculated based on the two-proportion $z$-test. See, for example, chapter 18 of Ramsey, Fred L. and Daniel W. Schafer. 
The Statistical Sleuth: A course in Methods of Data Analysis, 2nd ed. (Pacific Grove, CA, Duxbury, 2002.)

${ }^{23}$ M. Kryjevskaia, M. R. Stetzer, and P. R. L. Heron, "Is a simple measurement task a roadblock to student understanding of wave phenomena?," Phys. Teach. 51, 560-563 (2013).

${ }^{24}$ M. Kryjevskaia, M. R. Stetzer, and P. R. L. Heron, "Student understanding of wave behavior at a boundary: The limiting case of reflection at fixed and free ends," Am. J. Phys. 79(5), 508-516 (2011).

${ }^{25}$ R. B. Ekstrom, J. W. French, and H. H. Harman, Manual for Kit of Factor Referenced Cognitive Tests (Educational Testing Service, Princeton, NJ, 1976).

${ }^{26}$ As described in detail below, the Spaceships task has been used to gauge student understanding of Galilean relativity and elicit specific conceptual and reasoning difficulties. In prior investigations by the Physics Education Group, it has been found that contexts effective in eliciting student difficulties are also often productive for instruction.
${ }^{27}$ See M. Boas, "Events as the key to a graphic understanding of special relativity,” Am. J. Phys. 47, 938-942 (1979).

${ }^{28} \mathrm{We}$ encourage interested readers to consult an online suite of Instructor resources (see citation 20) for understanding and addressing issues relevant to the student intellectual engagement with the materials.

${ }^{29}$ For discussion of the development of this tutorial, see Karen Wosilait, Paula R. L. Heron, Peter S. Shaffer, and Lillian C. McDermott, "Development and assessment of a research-based tutorial on light and shadow," Am. J. Phys. 66, 906-913 (1998).

${ }^{30}$ In the authors' extensive experience administering the tutorials at UW, lecture instructors did not attend tutorial sections and rarely referred to the tutorial during the lecture. In addition, due to scheduling constraints, the tutorial topic did not always match the topic being covered in lecture.

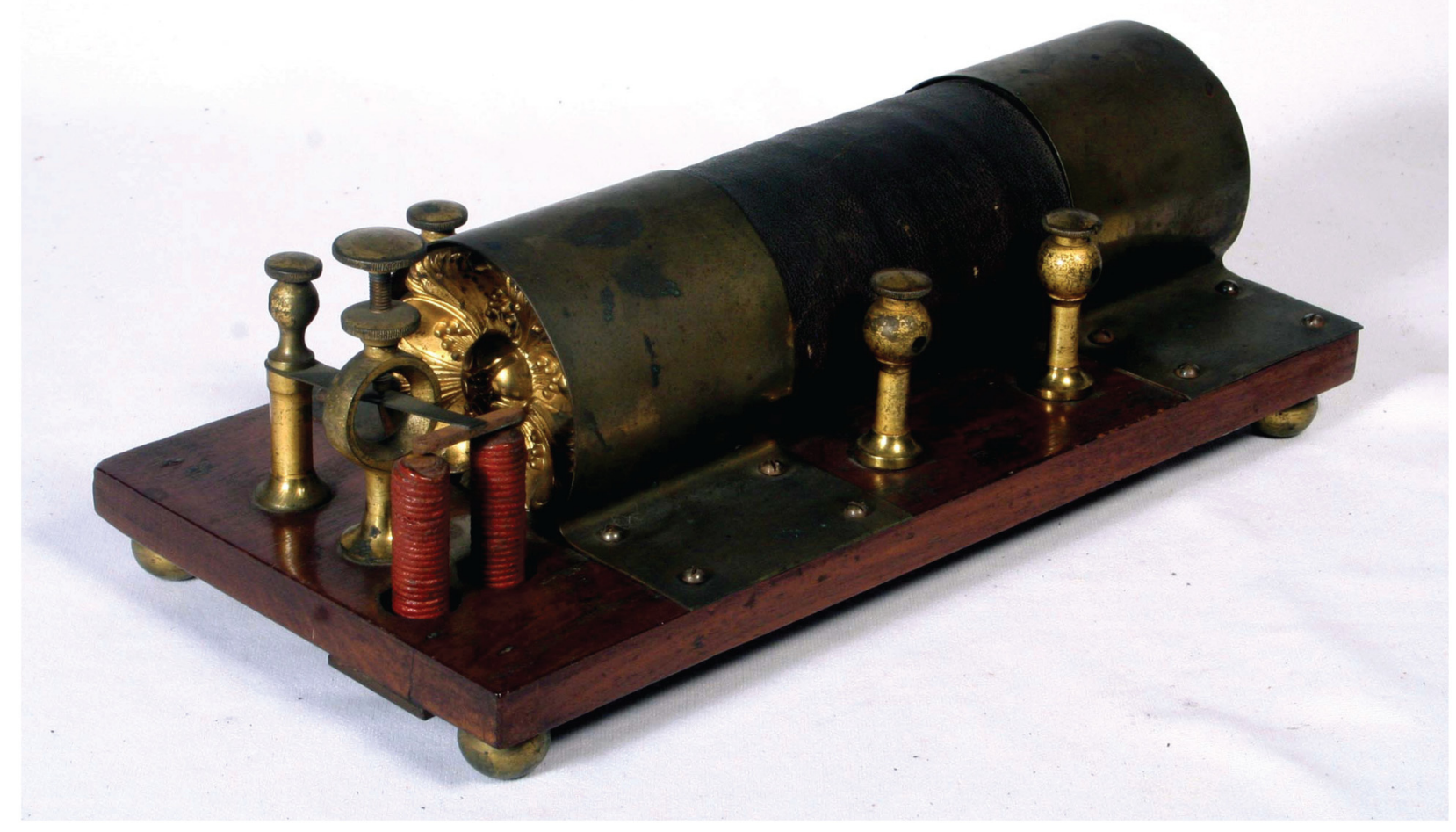

"Vibrating Shocker"

Charles Grafton Page (1812-1868) is usually regarded as the first electrical inventor in the United States, and was one of the developers of the induction coil. This piece of apparatus has resided for a number of years in my apparatus museum, and only recently was I able to identify it with Page. It first appears in the 1842 edition of Daniel Davis's Manual of Magnetism in the section on Medical Electricity and in the present form in the 1860 catalogue of Edward S. Ritchie of Boston, where it is listed as "Vibrating Shocker, or Double Helices; for showing the volta-electric induction of Faraday ... \$5.00" The main part of the device is a step-up transformer; on the right-hand side is a make and break system for changing direct current from a battery into pulsating current to feed the primary of the transformer. (Notes and photograph by Thomas B. Greenslade, Jr., Kenyon College) 